ARTICLE

\title{
A record thermoelectric efficiency in tellurium-free modules for low-grade waste heat recovery
}

Zhonglin Buํ, Xinyue Zhang ${ }^{1}$, Yixin $\mathrm{Hu}^{1}$, Zhiwei Chen ${ }^{1}$, Siqi $\mathrm{Lin}^{1}$, Wen $\mathrm{Li}^{1}$, Chong Xiao ${ }^{2} \&$ Yanzhong Pei(D) ${ }^{1 凶}$

Low-grade heat accounts for $>50 \%$ of the total dissipated heat sources in industries. An efficient recovery of low-grade heat into useful electricity not only reduces the consumption of fossil-fuels but also releases the subsequential environmental-crisis. Thermoelectricity offers an ideal solution, yet low-temperature efficient materials have continuously been limited to $\mathrm{Bi}_{2} \mathrm{Te}_{3}$-alloys since the discovery in 1950s. Scarcity of tellurium and the strong property anisotropy cause high-cost in both raw-materials and synthesis/processing. Here we demonstrate cheap polycrystalline antimonides for even more efficient thermoelectric waste-heat recovery within $600 \mathrm{~K}$ than conventional tellurides. This is enabled by a design of $\mathrm{Ni} / \mathrm{Fe} / \mathrm{Mg}_{3} \mathrm{SbBi}$ and $\mathrm{Ni} / \mathrm{Sb} / \mathrm{CdSb}$ contacts for both a prevention of chemical diffusion and a low interfacial resistivity, realizing a record and stable module efficiency at a temperature difference of $270 \mathrm{~K}$. In addition, the raw-material cost to the output power ratio in this work is reduced to be only $1 / 15$ of that of conventional $\mathrm{Bi}_{2} \mathrm{Te}_{3}$-modules.

\footnotetext{
${ }^{1}$ Interdisciplinary Materials Research Center, School of Materials Science and Engineering, Tongji Univ., 4800 Caoan Rd., Shanghai 201804, China. ${ }^{2}$ Hefei National Laboratory for Physical Sciences at the Microscale, University of Science and Technology of China, Hefei, Anhui 230026, P. R. China.

凶email: yanzhong@tongji.edu.cn
} 
M odern industries intensively consume energy. In various manufacturing and process plants, over $60 \%$ of total energy is dissipated as waste heat ${ }^{1,2}$. The hightemperature high-quality waste heat can easily be collected and re-used in industries. However, it is challenging to harvest and re-use the low-temperature waste heat (mostly emitted in the range of $<300^{\circ} \mathrm{C}^{3-5}$ ) through conventional energy conversion technologies because it is generally of low quality and low energy density ${ }^{5}$. This low-grade waste heat actually accounts for $50 \%$ of the total (Fig. 1a) ${ }^{6,7}$. As a clean and silent energy conversion technology, thermoelectric power generation enables a direct conversion of waste heat into useful electricity, which reduces fossil fuel consumption and releases the subsequential environmental crisis.

The conversion efficiency of a thermoelectric device mainly depends on the materials' figure of merit $z T=S^{2} T / \rho \kappa$, where $S, T$, $\rho, \kappa$ are Seebeck coefficient, absolute temperature, electrical conductivity and thermal conductivity, respectively. Obviously, this indicates the greater challenge for realizing a high $z T$ at low temperatures, and indeed $z T$ at mid-to-high temperatures are significantly improved in materials including $\mathrm{PbTe}^{8,9}$, Halfheusler ${ }^{10,11}, \mathrm{SiGe}^{12,13}$, and $\mathrm{GeTe}^{14-16}$. In the temperature range of low-grade waste heat $(<600 \mathrm{~K})$, high-performance thermoelectric materials have long been limited to $\mathrm{Bi}_{2} \mathrm{Te}_{3}$-alloys ${ }^{5,17}$. In fact, $\mathrm{Bi}_{2} \mathrm{Te}_{3}$-based thermoelectrics in both $\mathrm{n}$ - and p-type are so far the only materials being commercialized for recovering low-grade waste heat and refrigeration applications $s^{5,18,19}$.

Although $\mathrm{Bi}_{2} \mathrm{Te}_{3}$-alloys are thermodynamically stable at higher temperatures, the thermoelectric devices are limited to be properly operated below $450 \mathrm{~K}$, because of the strong detrimental bipolar effect ${ }^{5,19,20}$ induced by the narrow bandgap at $T>450 \mathrm{~K}$. This results in a typical efficiency of only $\sim 7 \%$ or less for available low-grade waste heat recovery devices (Fig. 1b) ${ }^{5,18}$. In addition, the scarcity of tellurium leads the cost and sustainability to be continuous concerns of conventional $\mathrm{Bi}_{2} \mathrm{Te}_{3}$ thermoelectrics. The maximum output power to the raw-material cost ratio for $\mathrm{Bi}_{2} \mathrm{Te}_{3}$ thermoelectrics is about $17 \mathrm{~W} / \$$ (power price ratio, Fig. $1 \mathrm{c}$ ) ${ }^{18}$. Moreover, the high thermoelectric performance of $\mathrm{Bi}_{2} \mathrm{Te}_{3}$-alloys is limited to along particular crystallographic directions at an expense of poor machinability due to the strongly anisotropic crystal structure, which further raises the device fabrication cost. Therefore, seeking cheap and high-efficiency alternatives for lowgrade waste heat recovery $(T<600 \mathrm{~K})$ has long been an anticipation in this field.

A construction of a thermoelectric device generally required both $\mathrm{n}$ - and p-type materials with similarly high performance. Recently, cheap n-type $\mathrm{Mg}_{3} \mathrm{Sb}_{2}{ }^{21-25}$ was reported not only to enable a better refrigeration effect as the n-leg of a device replacing $n$-type $\mathrm{Bi}_{2} \mathrm{Te}_{3}{ }^{26}$, but also to show a high single-leg efficiency of $\sim 10 \%$ for power generation at a source temperature of $T \sim 700 \mathrm{~K}^{27-29}$. Furthermore, a uni-couple device of $\mathrm{n}-\mathrm{Mg}_{3} \mathrm{Sb}_{2}$ and $\mathrm{p}-\mathrm{Bi}_{2} \mathrm{Te}_{3}$ materials show a high conversion efficiency of $9 \%$ using a source temperature of $\sim 573 \mathrm{~K}^{30}$. Things do not go so well for seeking p-type alternatives to $\mathrm{Bi}_{2} \mathrm{Te}_{3}$. Although p-type $\mathrm{MgAgSb}^{31,32}$ was reported to have a $z T$ comparable to $\mathrm{p}$-type $\mathrm{Bi}_{2} \mathrm{Te}_{3}$, and a single-leg device efficiency of $\sim 8 \%$ at a source temperature of $T \sim 550 \mathrm{~K}^{33}$, phase transitions in this compound with expensive Ag might bring extra challenges for mass production $^{33}$. Fortunately, p-type $\mathrm{CdSb}^{34,35}$ was reported to show a high average $z T>1$ at $T<600 \mathrm{~K}$, which is comparable to p-type $\mathrm{Bi}_{2} \mathrm{Te}_{3}$. Therefore, a device assembled by cheap materials of n-type $\mathrm{Mg}_{3} \mathrm{Sb}_{2}$ and p-type CdSb is expected to be a promising solution for efficient low-grade waste heat recovery without using $\mathrm{Bi}_{2} \mathrm{Te}_{3}$-alloys.

Here, we focus on both material- and device-level properties of $\mathrm{n}-\mathrm{Mg}_{3.1} \mathrm{Y}_{0.01} \mathrm{BiSb}$ and $\mathrm{p}-\mathrm{Cd}_{0.99} \mathrm{Ag}_{0.01} \mathrm{Sb}$, both of which consist of abundant elements and are optimized to show an average $z T$ $\left(z T_{\text {avg }}\right)$ of $>1$ within ambient temperature to $600 \mathrm{~K}$. In addition to a high material's $z T$, an electrically and thermally conductive but chemically inert contacts between thermoelectric materials and electrodes are essential to ensure a high device efficiency. Usually, a stack of multiple layers can be applied for a prevention of atomic diffusion, a release of thermal stress, and a reduction of contact resistance. These are enabled in this work by a one-step hot-pressing process for large cylinders of n-type and p-type containing $\mathrm{Ni}$ electrodes and diffusion barrier layers ( $\mathrm{Fe}$ for $\mathrm{Mg}_{3.1} \mathrm{Y}_{0.01} \mathrm{BiSb}$ and $\mathrm{Sb}$ for $\mathrm{CdSb}$, Fig. 2). The tellurium-free thermoelectric modules with a very high power-price ratio of $272 \mathrm{~W} / \$$ was assembled to show a high efficiency more than $8 \%$ at $T \leq 550 \mathrm{~K}$, using legs sliced from the hot-pressed cylinders. This offers great potentials of the tellurium-free thermoelectrics here as economic, sustainable, and efficient alternatives to conventional $\mathrm{Bi}_{2} \mathrm{Te}_{3}$-based ones for low-grade waste heat recovery.

\section{Results}

Tellurium-free legs fabricated and materials properties. The details on material synthesis, module fabrication (dimensions shown in Supplementary Table 1), characterizations, and property measurements (efficiency measurement setup in Supplementary Fig. 1) are given in the Supplementary. A copper bar with known thermal conductivity was used as a heat-flow meter within a temperature difference of $0.6-2.3 \mathrm{~K}$, which is determined by averaging 60 measurements with a relative standard deviation a

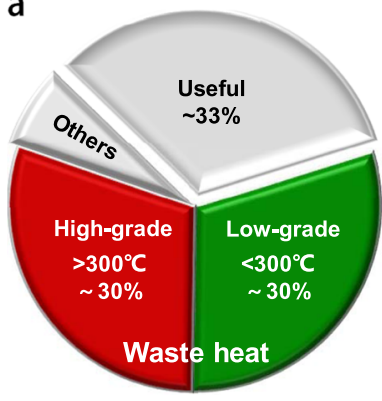

Total: $\sim 40$ trillion $\mathrm{kWh}$
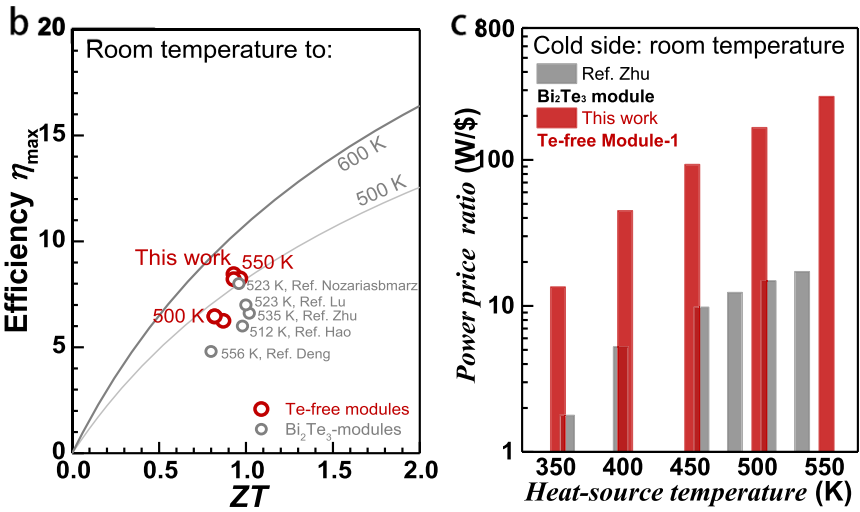

Fig. 1 Energy consumption distribution and thermoelectric performance. Energy consumption distribution indicating the huge proportion of low-grade waste heat $\left(T<300^{\circ} \mathrm{C}\right)^{7,47}(\mathbf{a})$, device $Z T$ dependent maximum efficiency $\left(\eta_{\max }\right)^{5,18,48,49}$ (b) and heat-source temperature-dependent power price ratio $(\mathrm{W} / \$)^{18}$ at a conventional leg size of $1.5 \times 1.5 \times 2 \mathrm{~mm}^{3}$ for Module-1 (c). 


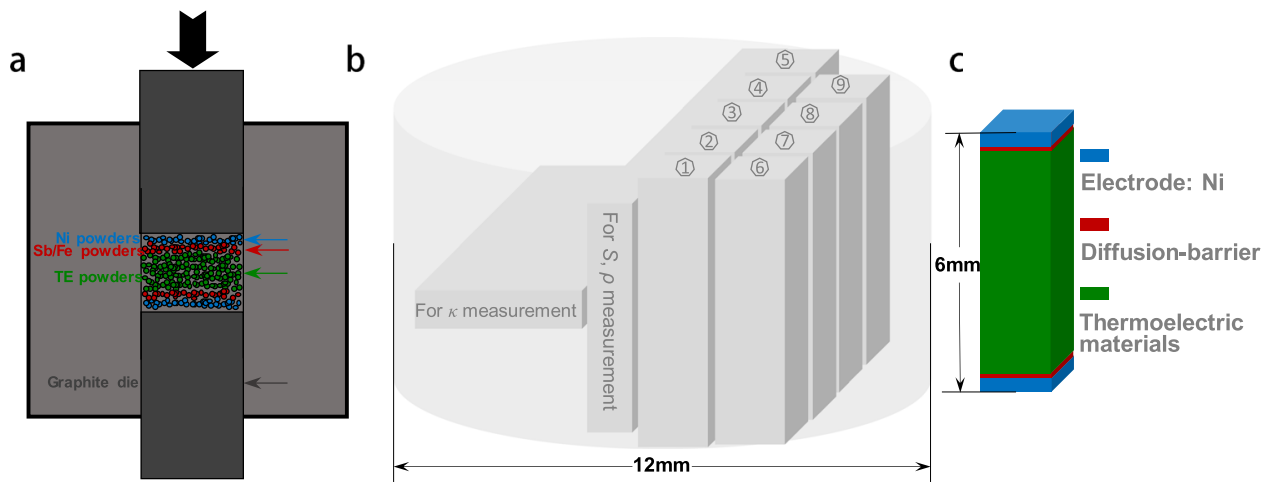

Fig. 2 Schematic of the tellurium-free legs fabricated. Schematic of the powder packing of the one-step hot-pressing (a), schematic slicing diagram of the cylinders (b), and schematic of a leg showing the contact structure (c).
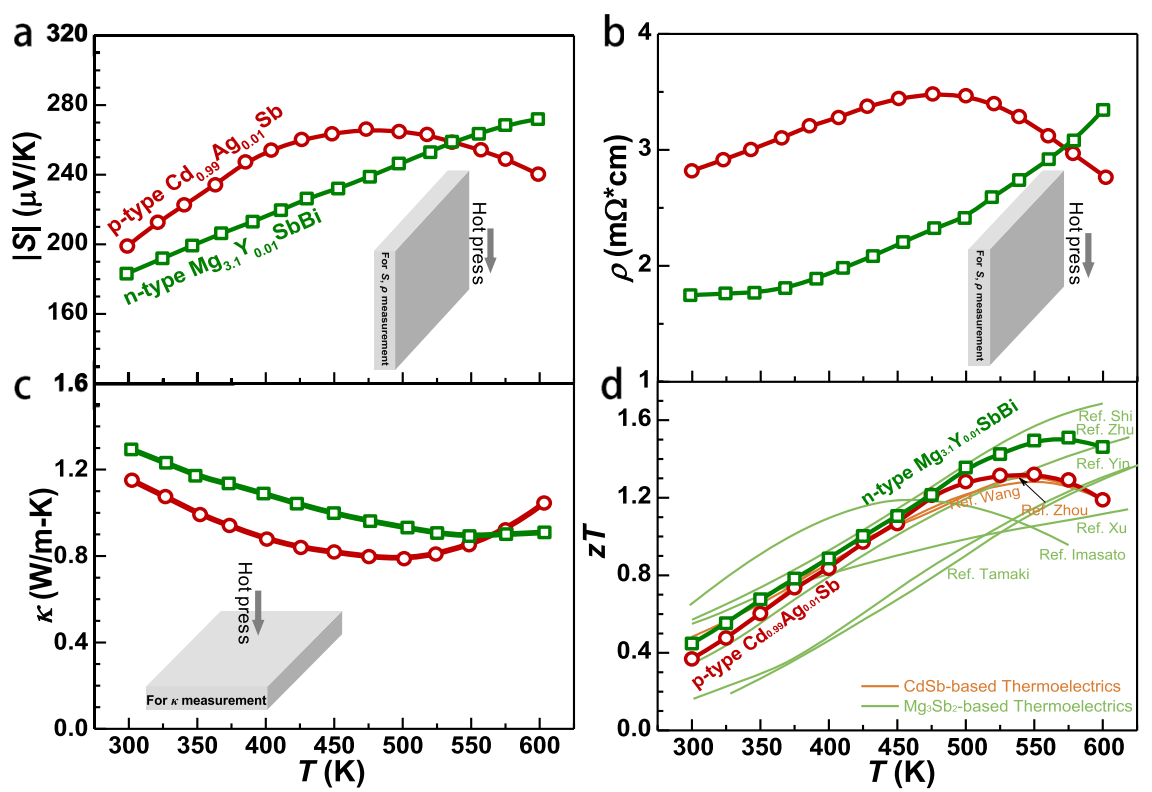

Fig. 3 Temperature dependent transport properties. Temperature-dependent Seebeck coefficient $(S)(\mathbf{a})$, electrical resistivity $(\rho)(\mathbf{b})$, thermal conductivity $(\kappa)(\mathbf{c})$, and thermoelectric figure of merit $(z T)$ (d) for $\mathrm{n}$-type $\mathrm{Mg}_{3.1} \mathrm{Y}_{0.01} \mathrm{SbBi}$ and $\mathrm{p}$-type $\mathrm{Cd}_{0.99} \mathrm{Ag}_{0.01} \mathrm{Sb}$ with a comparison to literature results $21,22,25,27,34,35,37,38$, where the inset schematically shows the electronic and thermal transport properties measured along the hot-press direction.

of $<3 \%{ }^{36}$ (Supplementary Table 2, Supplementary Fig. 2). Details on the estimated horizontal and vertical heat radiations, the response of the heat-flow meter and the stable open-circuit thermoelectromotive force are shown in Supplementary Fig. 3-6 and Supplementary Table 3. Details on calibrating the measurement system are shown in Supplementary Fig. 7-10, with comparisons to the results measured by commercial instruments from both the material and device levels. The hot-pressed cylinders are sliced along (for $\kappa$ measurement) and perpendicular (for $S, \rho$ measurement) to the pressure direction (Fig. 2b). The X-ray diffraction (XRD) patterns, scanning electron microscopy (SEM) images and corresponding energy dispersive spectroscopy (EDS) compositional mapping for n-type $\mathrm{Mg}_{3} \mathrm{SbBi}$ and p-type CdSb are shown in Supplementary Fig. 11. No obvious impurity peaks were observed from XRD patterns for both materials, indicating a good phase purity and SEM and EDS results further confirm a good homogeneity.

Temperature-dependent electronic and thermal transport properties of both $n-\mathrm{Mg}_{3.1} \mathrm{Y}_{0.01} \mathrm{BiSb}$ and $p-\mathrm{Cd}_{0.99} \mathrm{Ag}_{0.01} \mathrm{Sb}$, all measured along the hot-press direction, are shown in Fig. 3. This work obtains comparable thermoelectric performances to the literature results (Fig. 3d) 21,22,27,34,35,37,38. Although the $z T$ of both materials here are inferior to that of $\mathrm{Bi}_{2} \mathrm{Te}_{3}$ near room temperature, the much higher $z T$ at $450-600 \mathrm{~K}$ ensures a high average $z T$, leading these materials to be reasonable choices for power generation within 300-600 K (Supplementary Fig. 12, 13). This can be understood by the strong detrimental bipolar effect at $T>450 \mathrm{~K}^{5,19,20}$, induced by the narrow bandgap in $\mathrm{Bi}_{2} \mathrm{Te}_{3}-$ thermoelectrics.

The stability of the thermoelectric materials is primary for a stable module. Thermoelectric CdSb and $\mathrm{ZnSb}$ have been known since $1950 \mathrm{~s}^{39,40}$, yet never been assembled for a module. In this work, the safe operating temperature of $\mathrm{CdSb}$ was determined to be $\sim 550 \mathrm{~K}$ or below. In more details, XRD patterns for both ingot quenched form melt and annealed samples are given in Supplementary Fig. 14. Ingot quenched from melt actually contains $\mathrm{Cd}_{13} \mathrm{Sb}_{10}$ as the matrix with elemental $\mathrm{Sb}$ as an impurity phase. While the post-annealing at $673 \mathrm{~K}$ for 48 -hours enables a homogenous crystallization of CdSb phase. This is very consistent with the literature work ${ }^{35}$. In addition, the SEM images and the EDS mapping confirm a complete formation of $\mathrm{CdSb}$ phase within the temperature range focused on in this work (Supplementary Fig. 14). The electronic properties of two different CdSb samples aging at $550 \mathrm{~K}$ become much more stable, according to the $\sim 500$ 
measurements in about $250 \mathrm{~h}$ for each sample (Supplementary Fig. 15). Similarly, the properties of the mating n-type leg of $\mathrm{Mg}_{3} \mathrm{SbBi}$ are quite stable as well at an even higher aging temperature of $600 \mathrm{~K}$. Moreover, good stability in thermal conductivity is confirmed by the measurements before and after aging (Supplementary Fig. 16).

Module optimization and performances. To maximize the module efficiency, the ratio of cross-sectional areas of $\mathrm{p}$ - and n-type legs needs to be optimized to ensure both high performances of legs at the same current density ${ }^{41}$. This requires a geometric configuration of $\mathrm{n}$ - and p-type legs that satisfies the relation of $\left(L_{\mathrm{n}} A_{\mathrm{p}}\right) /$ $\left(L_{\mathrm{p}} A_{\mathrm{n}}\right)=\left(K_{\mathrm{n}} R_{\mathrm{p}} / K_{\mathrm{p}} R_{\mathrm{n}}\right)^{0.541}$. Here, $L, A, K$ and $R$ are the length, cross-sectional area, thermal conductance $(K=\kappa A / L)$ and electrical resistance $(R=\rho L / A)$, and superscripts $\mathrm{n}$ and $\mathrm{p}$ indicate the $\mathrm{n}$ - and p-type legs, respectively. Due to the similar Seebeck coefficient, electrical resistivity and thermal conductivity in both $n$-type $\mathrm{Mg}_{3} \mathrm{SbBi}$ and $p$-type CdSb within $300-550 \mathrm{~K}, A_{\mathrm{n}} / A_{\mathrm{p}}=1$ is eventually chosen to fabricate three $\mathrm{Mg}_{3} \mathrm{SbBi} / \mathrm{CdSb}$ thermoelectric modules with a leg size of $1.5 \times 1.5 \mathrm{~mm}^{2}$ in cross section. To establish a reliable temperature difference across the thermoelectric legs, the materials were chosen in length of $2 \mathrm{~mm}$ (for Module-1) or $4 \mathrm{~mm}$ (for Module-2 and 3), which also can maintain a reasonably small contribution $(<5 \%)$ of contact resistance to the internal resistance (Supplementary Fig. 17).

For a device, contact resistance needs to be minimized to ensure a low device internal resistance $\left(R_{\text {in }}\right)$ thus a maximum output power $\left(P_{\max }\right)$ and efficiency $(\eta)$. The electrical contact resistance $\left(R_{\mathrm{c}}\right)$ was estimated according to a linear resistance scanning measurement based on a four-probe technique ${ }^{42}$. Multiplying the contact resistance $\left(R_{\mathrm{c}}\right)$ with the contact area, the interfacial contact resistivity $\left(\rho_{c}\right)$ can be obtained ${ }^{43}$. In order to obtain a low contact resistance, as well as a robust bonding, various contact designs were designed (Supplementary Fig. 18, Supplementary Table 4). Among these metals, the contact resistivity of $\mathrm{Ni} / \mathrm{CdSb}$ structure is the lowest one. However, the $\mathrm{Ni}$ can easily react with $\mathrm{CdSb}$, leading to a significant aggregation of $\mathrm{Sb}$ at the boundary (Supplementary Fig. 19). This hints excess of $\mathrm{Sb}$ at the boundary might be helpful for reducing the diffusion. According to previous works showing a very low contact resistivity ${ }^{6,44}$, native elements or inter-compounds of the thermoelectric materials themselves seem to work well as efficient diffusion barrier layers with low interfacial contact resistivity. A sandwich structure of $\mathrm{Ni} / \mathrm{Sb} / \mathrm{CdSb}(\mathrm{Ni}$ as the electrode and $\mathrm{Sb}$ as the diffusion barrier layer) is chosen in this work since it enables the lowest interfacial contact resistivity $\left(\rho_{c}\right)$ of only $\sim 30 \mu \Omega \mathrm{cm}^{2}$ (Fig. 4, Supplementary Table 4). Previous literature reports a low $\rho_{\mathrm{c}}$ in $\mathrm{Fe} / \mathrm{Mg}_{3} \mathrm{Sb}_{2}{ }^{28}$. In this work, Fe and $\mathrm{Ni}$ were respectively used as the diffusion barrier and electrode of the n-type $\mathrm{Mg}_{3} \mathrm{SbBi}$ legs, and the obtained $\rho_{\mathrm{c}}$ of $\sim 12 \mu \Omega \mathrm{cm}^{2}$ is comparable to the literature results $^{28}$. The small difference of interfacial contact resistance between different legs indicates the rationality of the structure here in both $\mathrm{Ni} / \mathrm{Sb} / \mathrm{CdSb}$ and $\mathrm{Ni} / \mathrm{Fe} / \mathrm{Mg}_{3} \mathrm{SbBi}$ (Supplementary Fig. 20). Furthermore, the linearly increasing resistance with distance in the $\mathrm{CdSb}$ and $\mathrm{Mg}_{3} \mathrm{SbBi}$ layers indicate that the electrical conductivity of thermoelectric materials are almost constant throughout the scanned area, confirming the high homogeneity. In addition, SEM observation and EDS mapping indicate good bonding with negligible chemical diffusion in both p-type $\mathrm{CdSb}$ legs and n-type $\mathrm{Mg}_{3} \mathrm{SbBi}$ legs, suggesting the rationality of choices of diffusion barrier materials here (Fig. 4b, c).

The device properties for modules are shown in Fig. 5, Supplementary Fig. 21 and 22. The nice linearity of current $(I)$ versus output voltage $(V)$ suggests a nearly Ohmic device in this work. The intercept and slope represent the open-circuit voltage $\left(V_{\mathrm{oc}}\right)$ and the module's internal resistance $\left(R_{\mathrm{in}}\right)$, respectively. For comparisons, $R_{\text {in }}$ and $V_{\text {oc }}$ are also estimated according to the material's properties. The discrepancy between the estimated and measured $R_{\text {in }}$ can be ascribed to the contact resistance. The good agreement between measurement and estimation in $V_{\mathrm{oc}}$ of all modules suggests a negligible temperature difference loss at the contacts even though the thermoelectric materials vary in length. The increase in $R_{\text {in }}$ and $V_{\text {oc }}$ with increasing temperature difference can be respectively understood by the increase at high temperatures in resistivity and Seebeck coefficient of both $\mathrm{Cd}_{0.99} \mathrm{Ag}_{0.01} \mathrm{Sb}$ and $\mathrm{Mg}_{3.1} \mathrm{Y}_{0.01} \mathrm{BiSb}$.

The output power $(P)$ first increases with increasing current, reaches its maximum when the external load resistance matches with $R_{\text {in }}$, and then decreases. The maximum output power is $\sim 0.474 \mathrm{~W}$ at the working condition of $T_{\mathrm{h}}=550 \mathrm{~K}$ and $\Delta T=270$ $\mathrm{K}$ of Module-1, corresponding to a power density $\left(P_{\mathrm{d}}, \mathrm{P}\right.$ over the total sectional area of legs) as high as $15 \mathrm{~kW} / \mathrm{m}^{2}$. An exact fair comparison on output power $(P)$ or output power density $\left(P_{\mathrm{d}}\right)$ of different modules having different heights are difficult, because of the existence of contact resistance. To make the comparison more straightforward, Module-1 is fabricated with thermoelectric legs of $2 \mathrm{~mm}$ tall, which is very comparable in size to conventional $\mathrm{Bi}_{2} \mathrm{Te}_{3}$-modules ${ }^{5,18}$. In principle, specific maximum power density $\left(P_{\mathrm{d}} \times L \text {, with } L \text { as the leg length }\right)^{45}$, offers an advantage over $P_{\mathrm{d}}$, because it becomes length $L$ independent in case of zero contact resistance. $R_{\text {in }}$ increases with increasing $L$ (Supplementary Fig. 17), therefore, $P_{\mathrm{d}}$ is $L$-dependent. However, the product $P_{\mathrm{d}} \times L$ roughly remains unchanged, because the contact resistance $\left(R_{\mathrm{c}}\right)$ is overall small as compared to $R_{\mathrm{in}}$. The contribution of $R_{\mathrm{c}}$ to $R_{\text {in }}$ can be reduced by increasing $L$, leading $P_{\mathrm{d}} \times L$ to show a saturation as $L$ is large, rationalizing a comparison on $P_{\mathrm{d}} \times L$ between modules consisting of different thermoelectric materials ${ }^{46}$. Indeed, both $P_{\mathrm{d}}$ and $P_{\mathrm{d}} \times L$ of Module- 1 are comparable to those of $\mathrm{Bi}_{2} \mathrm{Te}_{3}$ modules ${ }^{5,18}$ with similar dimensions (Supplementary Fig. 23).

A maximum and stable high efficiency $\left(\eta_{\max }\right)$ of $>8 \%$ is realized at a hot-side temperature of $550 \mathrm{~K}$ and cold-side temperature of $280 \mathrm{~K}$ (Fig. 5, Supplementary Fig. 21). This efficiency is actually higher than any of the experimental results in various modules ever reported, which can be understood by the high $z T$ as well as the stable compatibility factor of these antimonides at these temperatures (Supplementary Fig. 12 and Fig. 24). Note the optimal currents for maximizing output power $P_{\max }$ and efficiency $\eta_{\max }$ are slightly different due to the Joule heating and Peltier effects that would increase the total heat flow (Fig. 5d). The measured heat flow (Q) at conditions of open circuit $(\eta=0)$ and of maximum efficiency $\left(\eta=\eta_{\max }\right)$ are quite comparable to the predictions (Supplementary Fig. 24a), and the discrepancy at high-temperature gradients can be ascribed to the vertical heat radiation from the unfilled hot-side to the cold-side substrate (Supplementary Fig. 4 and Fig. 5). Similarly, the measured $\eta_{\max }$ reasonably agrees with the prediction (Supplementary Fig. 24), indicating a nearly realization of the full potential of highperformance $\mathrm{CdSb} / \mathrm{Mg}_{3} \mathrm{SbBi}$ thermoelectric materials here. Note that a shorter leg length in Module-1 corresponds to a higher contact resistance ratio, thus a lower specific power density $\left(P_{\mathrm{d}} \times L\right)$ and a lower efficiency $\left(\eta_{\max }\right)$ as compared to that in Module- 2 with a longer leg length. Overall, the small deviation in measured and predicted $\eta_{\max }$ further suggests the rational design of the module in this work. Both horizontal and vertical heat radiations are taken into account here for estimating the efficiency, and the corresponding maximum efficiency are listed in Supplementary Table 3 for Module- 1 .

In addition to the high efficiency, the module in this work shows a very good stability, which is evidenced by continuous 

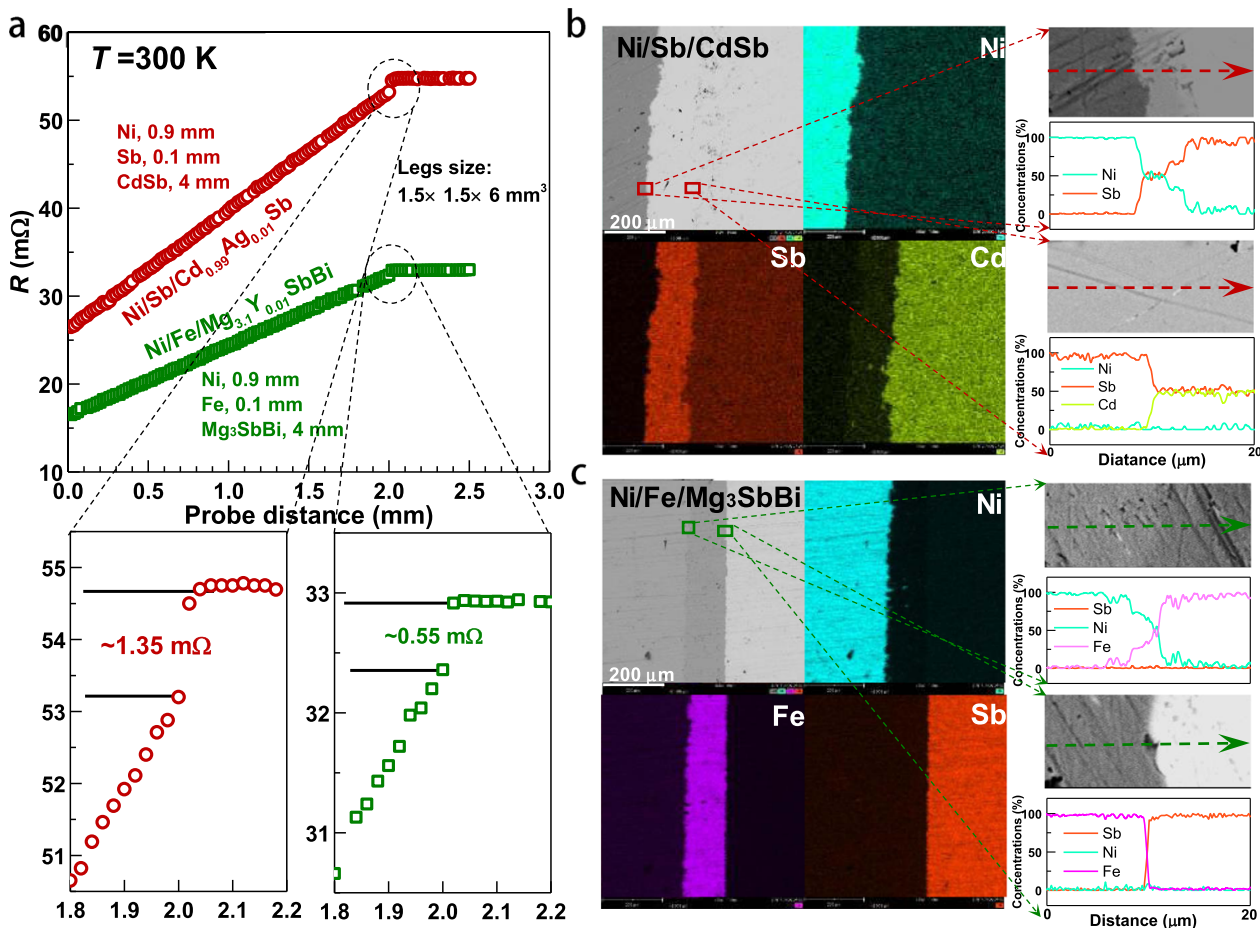

Fig. 4 Contact structure and resistance. Line scanning of resistance $(R)$ across the $\mathrm{Ni} / \mathrm{Sb} / \mathrm{CdSb}$ and $\mathrm{Ni} / \mathrm{Fe} / \mathrm{Mg}_{3} \mathrm{SbBi}$ interfaces for estimating the contact resistance (a), SEM images, EDS mapping, and EDS line scanning for the $\mathrm{Ni} / \mathrm{Sb} / \mathrm{CdSb}$ (b) and the $\mathrm{Ni} / \mathrm{Fe} / \mathrm{Mg}_{3} \mathrm{SbBi}$ junctions (c).

output power measurements under $555 \mathrm{~K}$ for $200 \mathrm{~h}$ (Supplementary Fig. 25). Due to the high stability of the thermoelectric materials at the safe operating temperature of $<\sim 550 \mathrm{~K}$, a continuous operating under this temperature for $\sim 200 \mathrm{~h}$ leads the module efficiency to decrease by only $<3 \%$, which actually falls in the measurement uncertainty range (Supplementary Fig. 25). Furthermore, the stability of $\mathrm{CdSb} / \mathrm{Mg}_{3} \mathrm{SbBi}$ module in this work is ensured by cycling test with a hot-side temperature of $555 \mathrm{~K}$. In more details, the hot-side temperature of Module- 1 ramps up from $350 \mathrm{~K}$ to $550 \mathrm{~K}$ for 15 times at a different constant output current for each time. Such a cycling test enables a maximum efficiency of $\sim 8 \%$ when the output current is about 0.8-1.2 A (Supplementary Fig. 26 and Fig. 27). This module efficiency is highly comparable to that of measured before and after the 15-times thermal cycling using a steady-temperaturegradient technique, which further confirms the excellent responsivity of the measurement setup. All these results ensured a stable module efficiency of $>8 \%$ at an operating hot-side temperature of $555 \mathrm{~K}$ has high thermal cycle stability. Furthermore, the interfacial contact resistance for the p-type CdSb leg increases form an initial $1.4 \mathrm{~m} \Omega$ to $2.1 \mathrm{~m} \Omega$ and then to $2.7 \mathrm{~m} \Omega$, due to a 14-days and an 80-days aging, respectively (Supplementary Fig. 20 and Fig. 28). Correspondingly for the n-type $\mathrm{Mg}_{3} \mathrm{SbBi}$ leg, contact resistance increases form an initial $0.6 \mathrm{~m} \Omega$ to $1.7 \mathrm{~m} \Omega$ and then to $2.4 \mathrm{~m} \Omega$. It is the overall small contact resistivity of $<60 \mu \Omega \mathrm{cm}^{2}$ guaranteeing the excellent long-term service stability (Supplementary Fig. 25 and Fig. 26). In addition, SEM observations taken after an eighty-day aging at $550 \mathrm{~K}$ consistently confirm the robust contacts with clear boundaries (Supplementary Fig. 29). Along with the detailed continuous measurements of electronic properties during aging/cycling, one could conclude that the materials and modules in this work show a very good stability.

This indicates the excellent chemical, thermal, electrical, and mechanical stability of the contacts in this work. Last but important, the abundance and yield of all constituent elements for $\mathrm{Mg}_{3} \mathrm{SbBi} / \mathrm{CdSb}$ module here are much larger than that in $\mathrm{Bi}_{2} \mathrm{Te}_{3}$-based ones, leading the raw-material cost of the $\mathrm{Mg}_{3} \mathrm{SbBi} /$ CdSb module is only one-tenth of that of conventional $\mathrm{Bi}_{2} \mathrm{Te}_{3}$ based modules (Supplementary Table 5). At a conventionally leg size of $1.5 \times 1.5 \times 2 \mathrm{~mm}^{3}$, the power price ratio of $272 \mathrm{~W} / \$$ realized in the antimonide module here is much higher than that of $\mathrm{Bi}_{2} \mathrm{Te}_{3}$-based one $(17 \mathrm{~W} / \$)^{18}$. Note the lower density of these antimonides offers an extra advantage for the power price ratio.

\section{Discussion}

In summary, a high thermoelectric module efficiency of $8 \%$ at a heat-source temperature of $T<550 \mathrm{~K}$ is realized using telluriumfree materials. This is enabled by the high thermoelectric performance of both n- and p-type materials as well as an effective interfacial contact design, the latter of which ensures a low contact resistance and a prevention of chemical diffusion. The constituent elements of these antimonides here are much cheaper and abundant as compared to those of conventional $\mathrm{Bi}_{2} \mathrm{Te}_{3}$-based modules. This work offers reasonable opportunities to challenge the long-term monopoly of $\mathrm{Bi}_{2} \mathrm{Te}_{3}$-based modules for efficient low-grade waste heat recovery.

\section{Methods}

Synthesis. Polycrystalline p-type $\mathrm{Cd}_{0.99} \mathrm{Ag}_{0.01} \mathrm{Sb}$ was synthesized by melting stoichiometric amount of high purity elements Cd (99.999\%), Ag (99.999\%), Sb $(99.99 \%)$ at $873 \mathrm{~K}$ for $5 \mathrm{~h}$, followed by quenching in cold water and annealing at $673 \mathrm{~K}$ for $48 \mathrm{~h}$. The obtained $\mathrm{Cd}_{0.99} \mathrm{Ag}_{0.01} \mathrm{Sb}$ ingot was ground into fine powder for further hot pressing. The $\mathrm{Cd}_{0.99} \mathrm{Ag}_{0.01} \mathrm{Sb}$ powders, $\mathrm{Sb}$ powders and $\mathrm{Ni}$ powders were loaded to a graphite die for one-step hot pressing at $658 \mathrm{~K}$ for $90 \mathrm{~min}$ under a uniaxial pressure of $\sim 65 \mathrm{MPa}$, obtaining a Ni/Sb/Cd ${ }_{0.99} \mathrm{Ag}_{0.01} \mathrm{Sb} / \mathrm{Sb} / \mathrm{Ni}$ cylinder with dimensions of $\sim 12 \mathrm{~mm}$ in diameter and $\sim 3$ or $6 \mathrm{~mm}$ in thickness (Ni layer: $\sim 0.4$ or $0.9 \mathrm{~mm}$, Sb layer: $\sim 0.1 \mathrm{~mm}, \mathrm{Cd}_{0.99} \mathrm{Ag}_{0.01} \mathrm{Sb}$ layer: $\sim 2$ or $4 \mathrm{~mm}$ ). The $\mathrm{Sb}, \mathrm{Fe}$, and $\mathrm{Ni}$ powders used as diffusion layers or electrodes cam with a particle size of 200 mesh.

Polycrystalline n-type $\mathrm{Mg}_{3.1} \mathrm{Y}_{0.01} \mathrm{SbBi}$ was synthesized by melting stoichiometric amount of high purity elements $\mathrm{Mg}$ (99.99\%), Y (99.99\%), Sb (99.99\%), Bi (99.99\%) in a sealed tantalum tube in a quartz ampoule at $1323 \mathrm{~K}$ for $5 \mathrm{~h}$, followed by quenching in cold water and annealing at $923 \mathrm{~K}$ for $48 \mathrm{~h}$. The sealing of the 

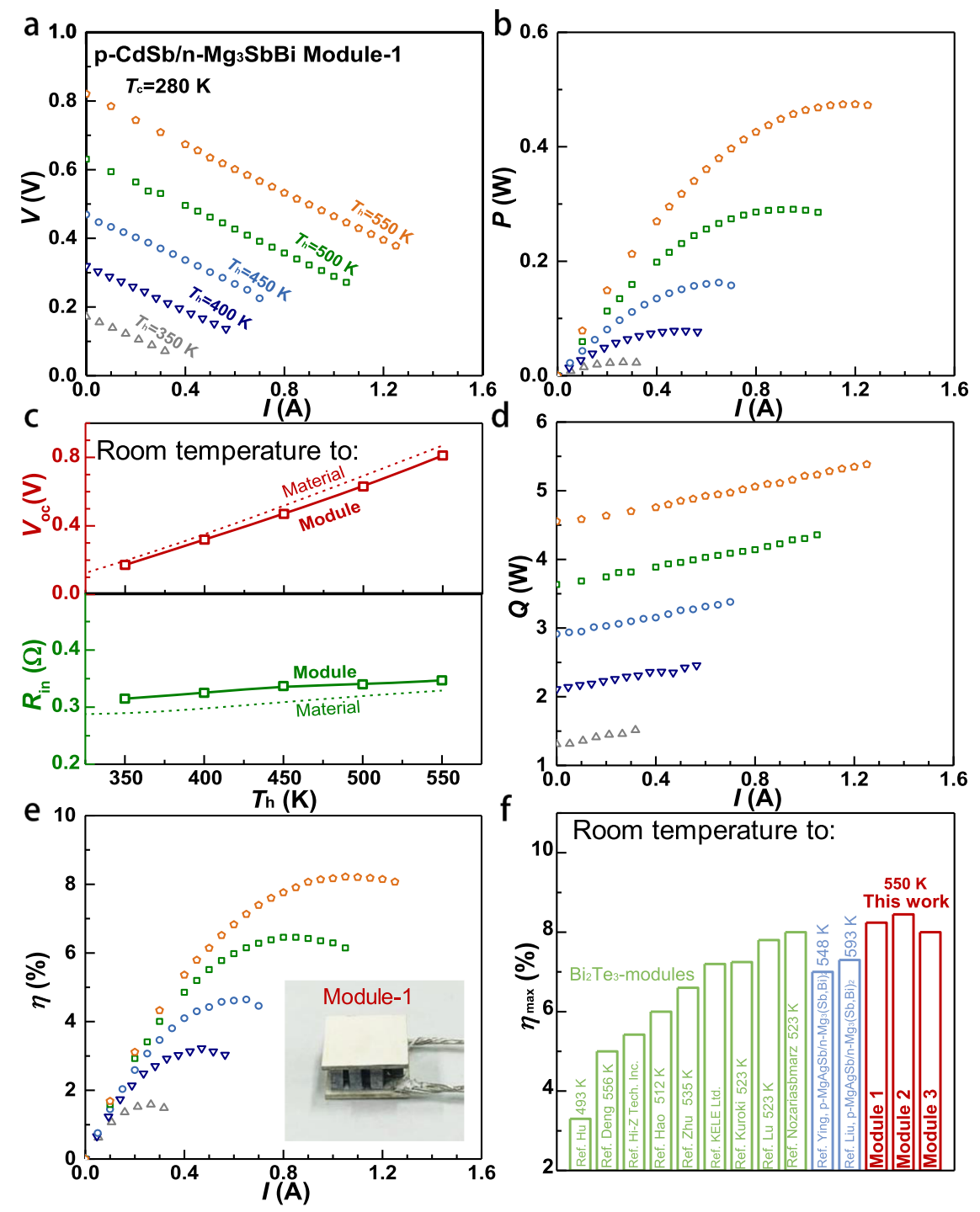

Fig. 5 Module properties. Current $(I)$ dependent output voltage $(V)(\mathbf{a})$ and output power $(P)(\mathbf{b})$, open-circuit voltage $\left(V_{\text {oc }}\right)$ and internal resistance $\left(R_{\text {in }}\right)$ $(\mathbf{c})$, heat-flow $(Q)$ from cold-side $(\mathbf{d})$, conversion efficiency $(\eta)(\mathbf{e})$ and its maximum $\eta_{\max }(\mathbf{f})$ under hot-side temperature of $550 \mathrm{~K}$ for $\mathrm{CdSb} / \mathrm{Mg}_{3} \mathrm{SbBi}$ modules. Literature results of $\mathrm{Bi}_{2} \mathrm{Te}_{3}$-modules and $\mathrm{MgAgSb} / \mathrm{Mg}_{3} \mathrm{SbBi}$-modules are included for a comparison $5,6,18,48-55$.

tantalum tube was done with an arc-melting system in argon with a pressure slightly lower than the atmosphere. Then the obtained $\mathrm{Mg}_{3.1} \mathrm{Y}_{0.01} \mathrm{SbBi}$ ingot was ground into powder. The $\mathrm{Mg}_{3.1} \mathrm{Y}_{0.01} \mathrm{SbBi}$ powders, Fe powders and Ni powders were loaded into a graphite die for one-step hot pressing at $823 \mathrm{~K}$ for 90 min under a uniaxial pressure of $\sim 90 \mathrm{MPa}$, obtaining a $\mathrm{Ni} / \mathrm{Fe} / \mathrm{Mg}_{3.1} \mathrm{Y}_{0.01} \mathrm{SbBi} / \mathrm{Fe} / \mathrm{Ni}$ cylinder with dimensions of $\sim 12 \mathrm{~mm}$ in diameter and $\sim 3$ or $6 \mathrm{~mm}$ in thickness (Ni layer: $\sim 0.4$ or $0.9 \mathrm{~mm}$, Fe layer: $\sim 0.1 \mathrm{~mm}, \mathrm{Mg}_{3.1} \mathrm{Y}_{0.01}$ SbBi layer: $\sim 2$ or $4 \mathrm{~mm}$ ).

The obtained $\mathrm{n}$ - and p-type cylinders were then sliced into plates and bars using a Wire-Cutting-Machine for characterizations, transport property measurements and module fabrication (Fig. 2).

Characterizations and transport property measurements. Phase compositions of both $\mathrm{p}-\mathrm{Cd}_{0.99} \mathrm{Ag}_{0.01} \mathrm{Sb}$ and $\mathrm{n}-\mathrm{Mg}_{3.1} \mathrm{Y}_{0.01} \mathrm{SbBi}$ samples were characterized by $\mathrm{X}$-Ray diffraction (XRD, DX2000). Both thermoelectric materials and junctions were characterized by Scanning Electronic Microscopy (SEM, Phenom Pro) equipped with an Energy Dispersive Spectrometer (EDS). Resistivity and Seebeck coefficient were simultaneously measured at various temperatures under helium. A four-probe Van Der Pauw technique was used for the resistivity measurement. The Seebeck coefficient was determined by the slope of thermopower versus temperature difference within $0-5 \mathrm{~K}$ recorded by two K-type thermocouples attached to the edges of a radial direction of the sample. The thermal conductivity $(\kappa)$ is estimated by $\kappa=d C_{\mathrm{p}} D$, where $d$ is the density, $C_{\mathrm{p}}$ is the heat capacity of the Dulong-Petit limit, $D$ is the thermal diffusivity measured using a laser flash technique (Netzsch LFA467) ${ }^{36}$. Transport property measurements were performed within $300-600 \mathrm{~K}$ and the uncertainty of each was about $5 \%$.
Reporting summary. Further information on research design is available in the Nature Research Reporting Summary linked to this article.

\section{Data availability}

The all data generated or analyzed in this study are included in the published article and its Supplementary Information.

Received: 26 October 2021; Accepted: 23 December 2021; Published online: 11 January 2022

\section{References}

1. Zebarjadi, M. et al. Perspectives on thermoelectrics: from fundamentals to device applications. Energy Environ. Sci. 5, 5147-5162 (2012).

2. Schierning, G. Bring on the heat. Nat. Energy 3, 92-93 (2018).

3. Wang, Z. Q. et al. Fluid selection and parametric optimization of organic Rankine cycle using low temperature waste heat. Energy 40, 107-115 (2012)

4. Wang, D. et al. Efficiency and optimal performance evaluation of organic Rankine cycle for low grade waste heat power generation. Energy 50, 343-352 (2013).

5. Hao, F. et al. High efficiency $\mathrm{Bi}_{2} \mathrm{Te}_{3}$-based materials and devices for thermoelectric power generation between 100 and $300^{\circ} \mathrm{C}$. Energ. Environ. Sci. 9, 3120-3127 (2016). 
6. Ying, P. et al. Towards tellurium-free thermoelectric modules for power generation from low-grade heat. Nat. Commun. 12, 1121 (2021).

7. National Energy Administration, http://www.nea.gov.cn (accessed April, 2021).

8. $\mathrm{Wu}, \mathrm{Y}$. X. et al. Lattice Strain Advances Thermoelectrics. Joule 3, 1276-1288 (2019).

9. Jood, P. et al. Excessively Doped PbTe with Ge-Induced Nanostructures Enables High-Efficiency Thermoelectric Modules. Joule 2, 1339-1355 (2018).

10. Yu, J. et al. Half-Heusler Thermoelectric Module with High Conversion Efficiency and High Power Density. Adv. Energy Mater. 10, 2000888 (2020).

11. Xing, Y. et al. High-efficiency half-Heusler thermoelectric modules enabled by self-propagating synthesis and topologic structure optimization. Energ. Environ. Sci. 12, 3390-3399 (2019).

12. Ahmad, S. et al. Boosting thermoelectric performance of p-type SiGe alloys through in-situ metallic $\mathrm{YSi}_{2}$ nanoinclusions. Nano Energy 27, 282-297 (2016).

13. Zhu, G. H. et al. Increased phonon scattering by nanograins and point defects in nanostructured silicon with a low concentration of germanium. Phys. Rev. Lett. 102, 196803 (2009).

14. Li, J. et al. Low-Symmetry Rhombohedral GeTe Thermoelectrics. Joule 2 , 976-987 (2018).

15. Liu, Z. H. et al. High Power Factor and Enhanced Thermoelectric Performance in Sc and Bi Codoped GeTe: Insights into the Hidden Role of Rhombohedral Distortion Degree. Adv. Energy Mater. 10, 2002588 (2020).

16. $\mathrm{Bu}, \mathrm{Z}$. et al. Dilute $\mathrm{Cu}_{2} \mathrm{Te}$-alloying enables extraordinary performance of r-GeTe thermoelectrics. Mater. Today Phys. 9, 100096 (2019).

17. Gayner, C. \& Kar, K. K. Recent advances in thermoelectric materials. Prog. Mater. Sci. 83, 330-382 (2016)

18. Zhu, B. et al. Realizing record high performance in n-type $\mathrm{Bi}_{2} \mathrm{Te}_{3}$-based thermoelectric materials. Energ. Environ. Sci. 13, 2106-2114 (2020).

19. Poudel, B. et al. High-Thermoelectric Performance of Nanostructured Bismuth Antimony Telluride Bulk Alloys. Science 320, 634-638 (2008).

20. Li, C. et al. Magnetism-induced huge enhancement of the room-temperature thermoelectric and cooling performance of p-type BiSbTe alloys. Energ. Environ. Sci. 13, 535-544 (2020).

21. Shi, X. et al. Extraordinary $\mathrm{n}$-Type $\mathrm{Mg}_{3} \mathrm{SbBi}$ Thermoelectrics Enabled by Yttrium Doping. Adv. Mater. 31, e1903387 (2019).

22. Imasato, K., Kang, S. D. \& Snyder, G. J. Exceptional thermoelectric performance in $\mathrm{Mg}_{3} \mathrm{Sb}_{0.6} \mathrm{Bi}_{1.4}$ for low-grade waste heat recovery. Energ. Environ. Sci. 12, 965-971 (2019).

23. Shu, R. et al. $\mathrm{Mg}_{3+\delta} \mathrm{Sb}_{x} \mathrm{Bi}_{2-x}$ Family: A Promising Substitute for the State-ofthe-Art n-Type Thermoelectric Materials near Room Temperature. Adv. Funct Mater, 1807235 (2018).

24. Zhang, X. et al. Electronic quality factor for thermoelectrics. Sci. Adv. 6, eabc0726 (2020).

25. Tamaki, H. et al. Isotropic Conduction Network and Defect Chemistry in $\mathrm{Mg}_{3+\text { delta }} \mathrm{Sb}_{2}$-Based Layered Zintl Compounds with High Thermoelectric Performance. Adv. Mater. 28, 10182-10187 (2016).

26. Mao, J. et al. High thermoelectric cooling performance of n-type $\mathrm{Mg}_{3} \mathrm{Bi}_{2}$ based materials. Science 365, 495-498 (2019).

27. Zhu, Q., Song, S., Zhu, H. \& Ren, Z. Realizing high conversion efficiency of $\mathrm{Mg}_{3} \mathrm{Sb}_{2}$-based thermoelectric materials. J. Power Sources 414, 393-400 (2019).

28. Yin, L. et al. Reliable N-type $\mathrm{Mg}_{3.2} \mathrm{Sb}_{1.5} \mathrm{Bi}_{0.49} \mathrm{Te}_{0.01} / 304$ stainless steel junction for thermoelectric applications. Acta Mater. 198, 25-34 (2020).

29. Shang, H. et al. N-type $\mathrm{Mg}_{3} \mathrm{Sb}_{2-x} \mathrm{Bi}_{x}$ with improved thermal stability for thermoelectric power generation. Acta Mater. 201, 572-579 (2020)

30. Liang, Z. et al. High thermoelectric energy conversion efficiency of a unicouple of n-type $\mathrm{Mg}_{3} \mathrm{Bi}_{2}$ and p-type $\mathrm{Bi}_{2} \mathrm{Te}_{3}$. Mater. Today Phys. 19, 100413 (2021).

31. Zheng, Y. et al. Extraordinary thermoelectric performance in MgAgSb alloy with ultralow thermal conductivity. Nano Energy 59, 311-320 (2019).

32. Liu, Z. et al. High thermoelectric performance of $a-M g A g S b$ for power generation. Energ. Environ. Sci. 11, 23-44 (2018).

33. Kraemer, D. et al. High thermoelectric conversion efficiency of MgAgSb-based material with hot-pressed contacts. Energ. Environ. Sci. 8, 1299-1308 (2015).

34. Zhou, B. et al. Transport Properties of CdSb Alloys with a Promising Thermoelectric Performance. ACS Appl Mater. Interfaces 11, 27098-27103 (2019).

35. Wang, S. et al. Anisotropic Multicenter Bonding and High Thermoelectric Performance in Electron-Poor CdSb. Chem. Mater. 27, 1071-1081 (2015).

36. $\mathrm{Bu}, \mathrm{Z}$. et al. Realizing a $14 \%$ single-leg thermoelectric efficiency in GeTe alloys. Sci. Adv. 7, eabf2738 (2021).

37. Xu, C. et al. Scalable synthesis of $\mathrm{n}$-type $\mathrm{Mg}_{3} \mathrm{Sb}_{2-x} \mathrm{Bi}_{x}$ for thermoelectric applications. Mater. Today Phys. 17, 100336 (2021).

38. Shi, X. et al. Revelation of Inherently High Mobility Enables $\mathrm{Mg}_{3} \mathrm{Sb}_{2}$ as a Sustainable Alternative to $\mathrm{n}-\mathrm{Bi}_{2} \mathrm{Te}_{3}$ Thermoelectrics. Adv. Sci. (Weinh.) 6 1802286 (2019).

39. Telkes, M. Solar Thermoelectric Generators. J. Appl Phys. 25, 765-777 (1954).
40. Smirous, K. et al. The influence of impurities on the electric and thermoelectric properties of CdSb single crystals. Czech. J. Phys. B 13, 350-357 (1963).

41. Chen, J., Yan, Z. \& Wu, L. The influence of Thomson effect on the maximum power output and maximum efficiency of a thermoelectric generator. J. Appl Phys. 79, 8823-8828 (1996).

42. Li, J. et al. Al-Si Alloy as a Diffusion Barrier for GeTe-Based Thermoelectric Legs with High Interfacial Reliability and Mechanical Strength. ACS Appl Mater. Interfaces 12, 18562-18569 (2020).

43. Liu, W. et al. Current progress and future challenges in thermoelectric power generation: From materials to devices. Acta Mater. 87, 357-376 (2015).

44. Muto, A. et al. Skutterudite Unicouple Characterization for Energy Harvesting Applications. Adv. Energy Mater. 3, 245-251 (2013).

45. Liang, J. et al. Flexible thermoelectrics: from silver chalcogenides to fullinorganic devices. Energ. Environ. Sci. 12, 2983-2990 (2019).

46. $\mathrm{Bu}, \mathrm{Z}$. et al. An over $10 \%$ module efficiency obtained using non-Bi2Te3 thermoelectric materials for recovering heat of $<600$ K. Energ. Environ. Sci. 14 6506-6513 (2021)

47. U.S. Energy Information Administration, http://www.eia.gov (accessed April, 2021).

48. Deng, $\mathrm{R}$. et al. High thermoelectric performance in $\mathrm{Bi}_{0.46} \mathrm{Sb}_{1.54} \mathrm{Te}_{3}$ nanostructured with ZnTe. Energ. Environ. Sci. 11, 1520-1535 (2018)

49. Lu, X. et al. High-Efficiency Thermoelectric Power Generation Enabled by Homogeneous Incorporation of MXene in $(\mathrm{Bi}, \mathrm{Sb})_{2} \mathrm{Te}_{3}$ Matrix. Adv. Energy Mater. 10, 1902986 (2019).

50. Kuroki, T. et al. Thermoelectric Generation Using Waste Heat in Steel Works. J. Electron Mater. 43, 2405-2410 (2014).

51. $\mathrm{Hu}, \mathrm{X}$. et al. Power Generation Evaluated on a Bismuth Telluride Unicouple Module. J. Electron Mater. 44, 1785-1790 (2015).

52. Company, K. L. Thermoelectric device type: KTGM161-18, http://www.kelk.co.jp (accessed April, 2021)

53. Technology.Inc, H.-z. Thermoelectric device type: The HZ-2 watt module, http://www.hi-z.com (accessed April, 2021).

54. Nozariasbmarz, A. et al. Bismuth Telluride Thermoelectrics with $8 \%$ Module Efficiency for Waste Heat Recovery Application. iScience 23, 101340 (2020).

55. Liu, Z. et al. Demonstration of ultrahigh thermoelectric efficiency of $\sim 7.3 \%$ in $\mathrm{Mg}_{3} \mathrm{Sb}_{2} / \mathrm{MgAgSb}$ module for low-temperature energy harvesting. Joule $\mathbf{5}$ 1196-1208 (2021)

\section{Acknowledgements}

This work is supported by the National Natural Science Foundation of China (Grant No. T2125008 Y. P., 51772215 Y. P., 52022068 W. L., 52001231 S. L.), the National Key Research and Development Program of China (2018YFB0703601 Y. P.), the Innovation Program of Shanghai Municipal Education Commission (2021-01-07-00-07E00096 Y. P.), the Hefei National Laboratory for Physical Sciences at the Microscale (KF2020007 Y. P.), the Shanghai Natural Science Foundation (19ZR1459900 W. L.) and the China Postdoctoral Science Foundation Projects (2019M661612 S. L.). The authors thank Prof. Huaizhou Zhao from the Chinese Academy of Sciences, Institute of Physics for support on the Mini-PEM measurements.

\section{Author contributions}

Y.P. designed this work. Z.B. and S.L. prepared the thermoelectric materials and measured the transport properties. Z.B. assembled the modules and measured the performance. Z.C. and Y.H. helped measure the contact resistance. All authors discussed the results and contributed to the data analyses. Z.B., X.Z., W.L., C.X. and Y.P. wrote and edited the manuscript.

\section{Competing interests}

The authors declare no competing interests.

\section{Additional information}

Supplementary information The online version contains supplementary material available at https://doi.org/10.1038/s41467-021-27916-y.

Correspondence and requests for materials should be addressed to Yanzhong Pei.

Peer review information Nature Communications thanks Tsutomu Kanno and the other anonymous reviewer(s) for their contribution to the peer review of this work.

Reprints and permission information is available at http://www.nature.com/reprints

Publisher's note Springer Nature remains neutral with regard to jurisdictional claims in published maps and institutional affiliations. 
(c) (i) Open Access This article is licensed under a Creative Commons Attribution 4.0 International License, which permits use, sharing, adaptation, distribution and reproduction in any medium or format, as long as you give appropriate credit to the original author(s) and the source, provide a link to the Creative Commons license, and indicate if changes were made. The images or other third party material in this article are included in the article's Creative Commons license, unless indicated otherwise in a credit line to the material. If material is not included in the article's Creative Commons license and your intended use is not permitted by statutory regulation or exceeds the permitted use, you will need to obtain permission directly from the copyright holder. To view a copy of this license, visit http://creativecommons.org/ licenses/by/4.0/.

(C) The Author(s) 2022 